\title{
Effects of meteorological parameters on COVID-19 transmission trends in Bangladesh
}

\author{
S. K. Pal' ${ }^{1}$ - M. H. Masum ${ }^{1}$
}

Received: 19 August 2020 / Revised: 19 May 2021 / Accepted: 31 May 2021 / Published online: 6 June 2021

C) Society for Environmental Sustainability 2021

\begin{abstract}
Understanding the influence of meteorological parameters in relation to COVID-19 transmission may be a convenient way to predict the ongoing pandemic towards its adaptive control measures. This study aims to explore the association between COVID-19 cases and meteorological parameters and to predict COVID-19 transmission for an extended period covering different climatic patterns. The number of COVID-19 cases, daily records of rainfall, temperature, relative humidity and wind speed data were collected for April and May 2020 from the eight major divisions in Bangladesh. The basic statistical analyses and auto regressive integrated moving average (ARIMA) using SPSS tool were applied to evaluate and explore association between meteorological parameters and COVID-19 cases and its transmission trend. A greater number of significant positive associations $(r=0.24-0.58)$ is found to exist between the relative humidity and COVID-19 cases across the cities, while with temperature both positive and negative associations ( $\mathrm{r}=-0.23$ to 0.72$)$ were revealed. Furthermore, both the rainfall and wind speed exhibit positive correlations. ARIMA model portrayed predictive trend of COVID-19 transmission, from its inception on 8 March 2020 to September 2020, in Bangladesh. The month of July showed the highest daily COVID-19 cases prior to lowering at steady rate till September illustrating the influnce of meteorological parameters.
\end{abstract}

Keywords COVID-19 $\cdot$ Temperature $\cdot$ Rainfall $\cdot$ Humidity $\cdot$ Wind speed $\cdot$ ARIMA

\section{Introduction}

The appearance and thrust of SARS-Cov-2 virus are harsh reality in the world since its first appearance in Wuhan, Hubei Province of China at the end of 2019. Till the date of writing of this manuscript, over 3 million people in 185 countries with different climatic and geographical regions have been affected by this virus. The novel coronavirus is highly transmissible in by direct contact or staying closer than 3-6 $\mathrm{m}$ of infected person. Among a few measures to avoid its transmission, maintaining social distance, wearing masks, washing hands and cloths are being advised by the World Health Organisation (WHO) and the respective health organizations locally and internationally. With a baffling

\footnotetext{
S. K. Pal

sudip@ cuet.ac.bd

M. H. Masum

mehedi.ce.cuet@gmail.com

1 Department of Civil Engineering, Chittagong University of Engineering \& Technology (CUET), Raozan, Pahartali, Chattogram 4349, Bangladesh
}

situation of coronavirus attack, different countries had initiated lockdown measures at first instance against its spreading and imposed health regulations advised by the WHO. In relation to this, initially three cases of COVID-19 infection were registered on March 8, 2020 in Bangladesh (IEDCR 2020). Thereafter, considering the increased number of cases and as advised by the WHO, the Government of Bangladesh (GoB) declared an almost 10 days complete shutdown on 16 March 2020 to be executed from 26 March 2020 to 4 April 2020, at first instance. However, the lockdown continued till 30 May 2020 following six more declarations of lockdown (Shawon 2020). While the lockdown measures resulted in rejuvenation of environment, the country's economy was significantly during this period. Subsequently, a decision to resume garment industries, a major economic head, maintaining health regulations, on 26 April, 2020, eventually put the lockdown measures and effects go in vain (Haque and Ahamad 2020). Moreover, starting other businesses as usual from 31 May 2020, Bangladesh saw its worst scenarios of affected cases with an average of approximately $3 \%$ of total tests conducted and $1.8 \%$ incremental rate of total affected, along with the positive trends in death tolls 
(IEDCR 2020). The figures were not as hopeless as compared with other countries, however, no positive picture is visible even after 110 days since its arrival in Bangladesh. In contrast, putting ban on people movement and closing down the business activities during lockdown period, the benefits to environment, in particular with lowering of air pollutants were reported and are documented from different regions (Kerimray et al. 2020; Masum and Pal 2021; Menebo 2020; Shahzad et al. 2020; Tobías et al. 2020), illustrated the magnitudes of benefits that are found to vary with different urban settings, population density, income level and meteorological backgrounds.

Considering the climatic variability exists in different parts of the world and to address the question whether climatic factors have influenced spreading of SARS-Cov-2 virus, a few recent studies are found reporting the relationship coronavirus disease 2019 (COVID-19) with climatic variables (Biktasheva 2020; Ma et al. 2020; Menebo 2020; Qi et al. 2020). For example, Ahmadi et al. (2020) investigated the effects of climatic parameters on COVID-19 outbreak in Iran and found that temperature and rainfall have positive relationship, while that with the humidity, wind speed and solar radiation were negative in terms of the number of infected cases. Another study by Biktasheva (2020) found that local air humidity has negative correlation with COVID-19 mortality in German federal states. In this line, positive correlation for diurnal temperature $(r=0.44)$ but negative for relative humidity ( $\mathrm{r}=-0.32$ ) with COVID-19 daily mortality counts in Wuhan, China were reported by Ma et al. (2020). This study also revealed that absolute humidity has a positive correlation with the death counts. In contrast, Qi et al. (2020) reported that both temperature and humidity are negatively correlated with COVID-19 transmission in Mainland China, and very similar findings with climatic variables have been reported by Şahin (2020) for 9 major cities in Turkey. Furthermore, Menebo (2020) noted the maximum, minimum, average temperature, and wind speed have positive connotation with daily new cases, while the precipitation exhibited negative association in Oslo, Norway. Another study by Tosepu et al. (2020) reported that the temperature, humidity and rainfall exhibit positive association with the COVID-19 cases in Jakarta, Indonesia. All these studies claimed the association of climatic factors on COVID-19 cases and death tolls. It is clear from the outcomes of these studies that the climatic parameters might have associations with COVID-19 cases and the variabilities in transmission and the death tolls are not unexpected in different regions; hence, a few more local/regional studies may not only further help in consolidating the impact of climatic patterns from the less reported countries/regions but also to be a useful way for adopting appropriate control measures. Hence, it is worth to investigate the effects of meteorological parameters on cases and death toll to predict the probable scenarios. To best of our knowledge the prediction of the ongoing pandemic pattern with climatic variables are not yet to explored fully. Unlike other studies, this study also explored precipitation influences as an additional climatic variable along with other variables aligned with aforesaid studies on COVID-19 cases. Also, study addresses whether there exists the variability within the country with respect to different climatic zones in eight administrative divisions in Bangladesh. Furthermore, the study explores the probability trend of COVID-19 transmission using statistical tools to portray the association of COVID-19 cases with climatic variables, that can be helpful to check, plan ahead.

\section{Methodology}

\section{Study area}

Bangladesh (as seen in Fig. 1) is situated in $20^{\circ} 34^{\prime}$ North latitude and $92^{\circ} 41^{\prime}$ East longitude. The country is surrounded by the Bay of Bengal in the south, the Assam Hills in the east and lofty Himalayas to the north. Bangladesh is in the tropical monsoon region with warm temperature and high humidity under with four major seasons namely, pre-monsoon (March-May), monsoon (June-September), post-monsoon (October-November) and winter (December-February). Except winter season, the annual maximum temperature of the country ranges between 30 and $40{ }^{\circ} \mathrm{C}$ during the dry, humid and warm period including rainfall, whereas the average temperature is seen around $10^{\circ} \mathrm{C}$ during the winter season. The mean annual rainfall of the country is about $2300 \mathrm{~mm}$, whilst the majority of the areas receives more than $2000 \mathrm{~mm}$ rainfall that confirms generally the even distribution across the different regions. Bangladesh has eight administrative divisions, namely Barisal (BAR), Chittagong (CTG), Dhaka (DHK), Khulna (KHU), Mymensingh (MYM), Rajshahi (RAJ), Rangpur (RAN) and Sylhet (SYL).

\section{Data collection}

Daily data of rainfall, temperature, relative humidity and wind speed of 8 divisional cities in Bangladesh was collected from the Bangladesh Meteorological Department (BMD) for the months of April and May 2020 (BMD 2020). The number of COVID-19 infected cases for the same period was collected from the Institute of Epidemiology, Disease Control and Research (IEDCR) and Directorate General of Health Services (DGHS) (DGHS 2020; IEDCR 2020).

\section{Statistical analyses}

Descriptive statistics, such as mean, range, coefficient of variation $(\mathrm{CV})$, trend analyses were performed using SPSS 
Fig. 1 Map showing the eight Divisions of Bangladesh

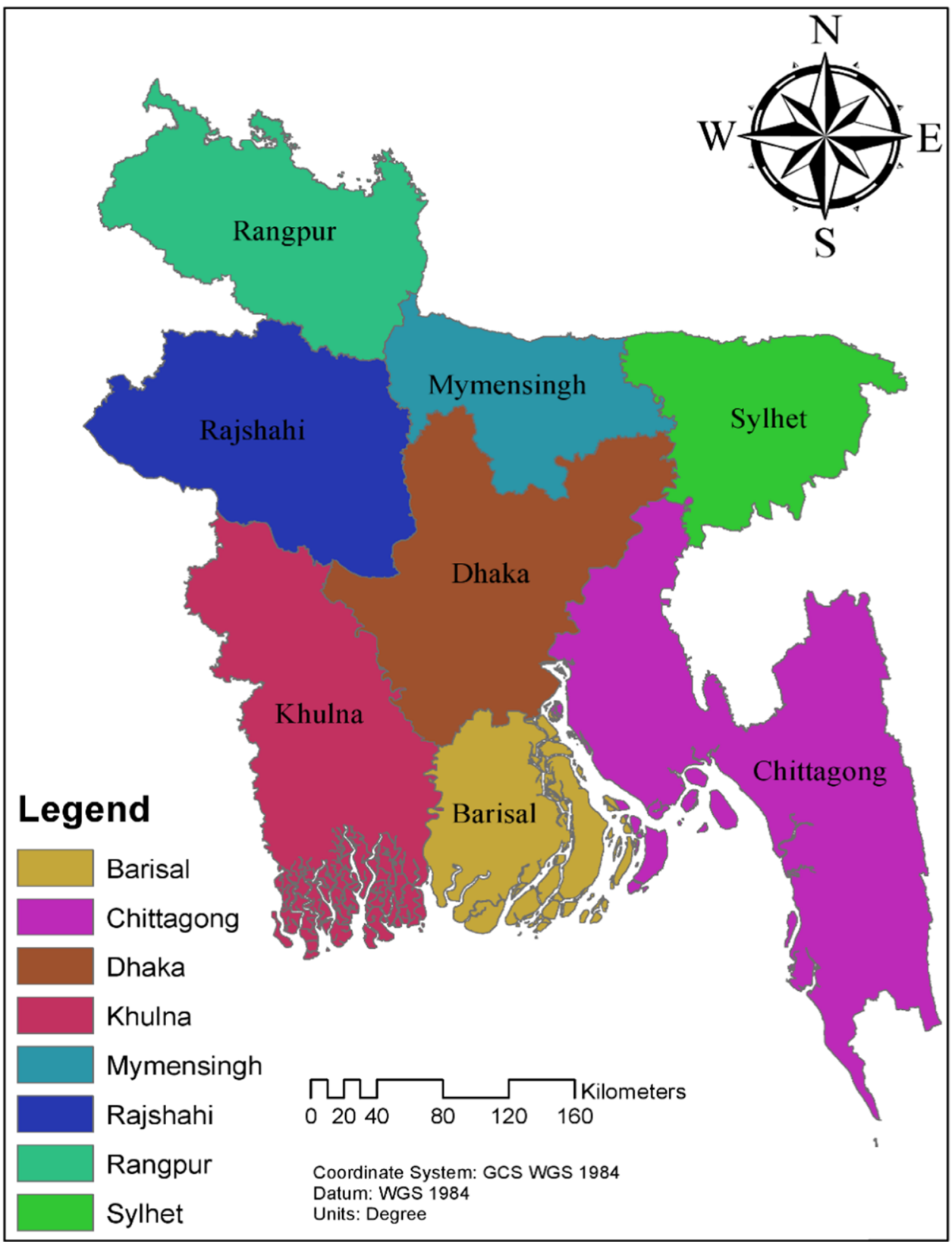

version 20. Due to variable nature of different climatic parameters, and as suggested by others for alike studies elsewhere in Norway (Menebo 2020), Turkey (Şahin 2020), Indonesia (Tosepu et al. 2020), Singapore (Pani et al. 2020), USA (Bashir et al. 2020), the Spearman's rank correlation analysis was performed to evaluate the relationship between the different climatic parameters (i.e., rainfall, temperature, humidity, wind speed etc.) and COVID-19 variables (i.e., COVID-19 cases). During correlation analysis, along with the current date COVID-19 cases with same day climatic variables, the climatic parameters that are lagged by 3,7 , 14 days, were also considered based on the assumption that the people got affected on date may not necessarily exposed to same day climatic parameters, as symptom of COVID-19 positive cases initiation takes couple of days to 2 weeks. The following equation was used to compute the Spearman's rank correlation coefficients (Spearman 2008).

$r_{s}=1-6 \frac{\sum d_{i}^{2}}{n\left(n^{2}-1\right)}$

where $n$ indicates the number of alternatives, and $d_{i}$ represents the difference between the ranks of two parameters. In this study, confidence intervals of $95 \%$ and $99 \%$ ( $p<0.05$, $\mathrm{p}<0.01$ ) are considered for the acceptable levels of association between any two variables. 


\section{Prediction and forecasting of COVID-19 cases}

In order to investigate the trends of COVID-19 cases in relation to climatic parameters, the Auto Regressive Integrated Moving Average (ARIMA) model was used. The model is simple yet powerful tool that depicts a stochastic time series model that can be used to train with present data to predict the future points. Autoregressive, integrated and moving average are three key factors of ARIMA model that guide to evaluate and select the coefficients in an iterative way and recursively. The stationarity of the data is prerequisite, and hence, the stationarity tests were conducted first for the confirmed COVID-19 cases for the duration of the study by plotting the residual Auto Correlation Function (ACF) and residual Partial Auto Correlation Function (PACF) as shown in Fig. 2. IBM-SPSS version 20 has been used as it developed ARIMA model using Box-Jenkins's algorithm approaches. In ARIMA (p, d, q) model, three predictor variables are used to predict and forecast the data, as mentioned earlier, where $\mathrm{p}$ refers the number of autoregressive orders, $d$ is the order of differencing applied to the series and q refers to the number of moving average orders of the data series. As seen in Fig. 2, the COVID-19 positive cases have been found inconsistent and nonstationary in nature, as the spikes have crossed the upper and lower boundary levels. Several ACF and PACF have been evaluated as obtain from a number of trials for different $\mathrm{p}, \mathrm{d}$, and $\mathrm{q}$ values until the spikes in ACF and PACF fall within upper and lower boundary limits prior to future prediction. The final trial in this sequence is shown in Fig. 3.

Furthermore, the forecasting of future COVID-19 cases based on present trend ARIMA $(35,0,0)$ model was used for future prediction. The stationary $R$ squared $\left(R^{2}\right)$ and ordinary $\mathrm{R}$ squared $\left(\mathrm{R}^{2}\right)$ were used to determine the accuracy of the model for each case. This study found the stationary $R$ squared $\left(R^{2}\right)$ is 0.941 in comparison to the ordinary $R$ squared $\left(\mathrm{R}^{2}\right)$ of 0.828 for prediction of the COVID-19 positive cases. The stationary $\mathrm{R}^{2}$ illustrates the better consistency for predictive trends or seasonal patterns than ordinary $\mathrm{R}^{2}$ (Figs. 2 and 3).

\section{Results and discussion}

\section{Descriptive statistics of climatic parameters}

Table 1 presents the descriptive statistics of the temperature $(\mathrm{T})$, relative humidity $(\mathrm{Rh})$, precipitation $(\mathrm{R})$ and wind speed $(\mathrm{u})$ as obtained from the daily records for the studied duration of eight divisions in Bangladesh. Along with these, total number of COVID-19 positive cases for March to May 2020 are also reported in Table 1. As seen in Table 1, the weather is in general warm with relatively high humidity with a few occasional precipitations across the sites. The variation of the mean temperature, relative humidity, precipitation and wind speed across the sites are in the range of $28-32{ }^{\circ} \mathrm{C}, 49$ to $67 \%, 0.3-2.1 \mathrm{~mm}$ and $6.9-15.8 \mathrm{~km} \mathrm{~h}^{-1}$, respectively, portraying somewhat variability across the sites. Based on the total registered COVID-19 positive cases during studied duration (April to May 2020), it has been seen that the cases are significantly higher in Dhaka and Chittagong in comparison to other major cities (see Table 1). This attributes to population density, very unplanned urban settings and commercial activities with these two largest cities in Bangladesh. The relatively high temperature and humidity with little
Fig. $2 \mathrm{ACF}$ and PACF before calibration (Data is found nonstationary)
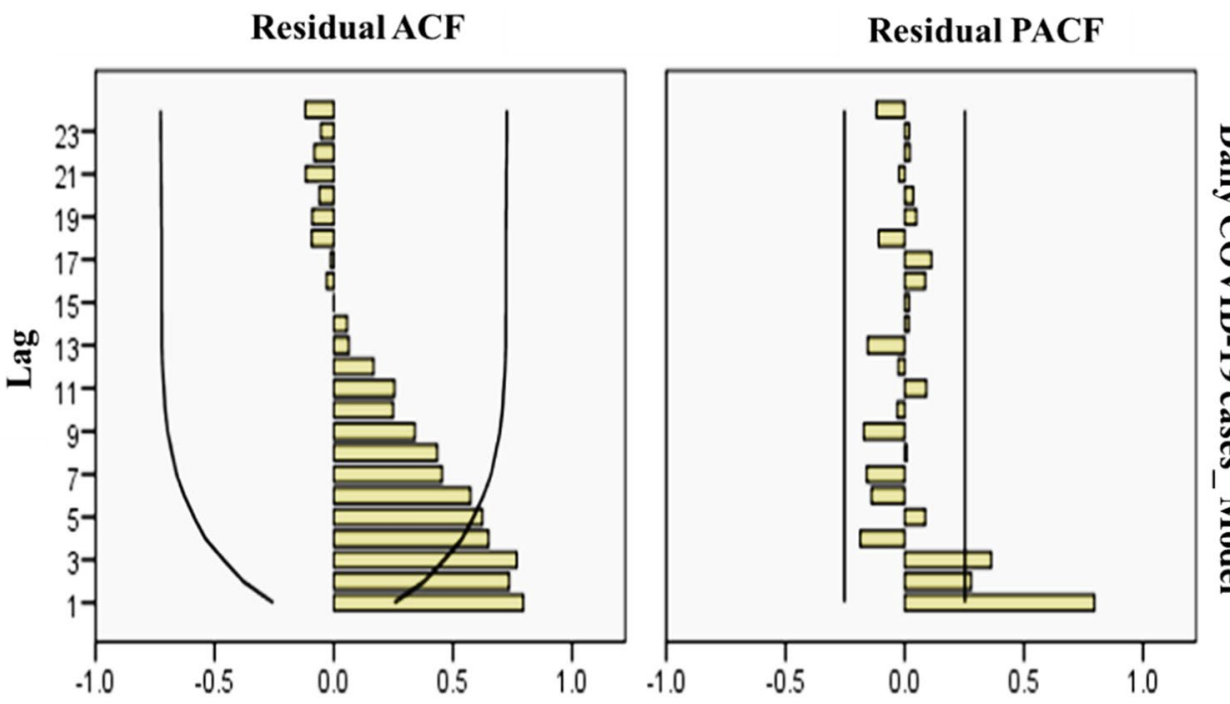

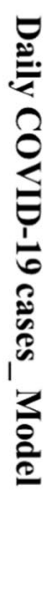

Residual 
Fig. 3 ACF and PACF after calibration with $\mathrm{p}, \mathrm{d}$ and $\mathrm{q}$ values
Table 1 Descriptive statistics of the climatic variables along with COVID-19 registered cases in Bangladesh in AprilMay 2020

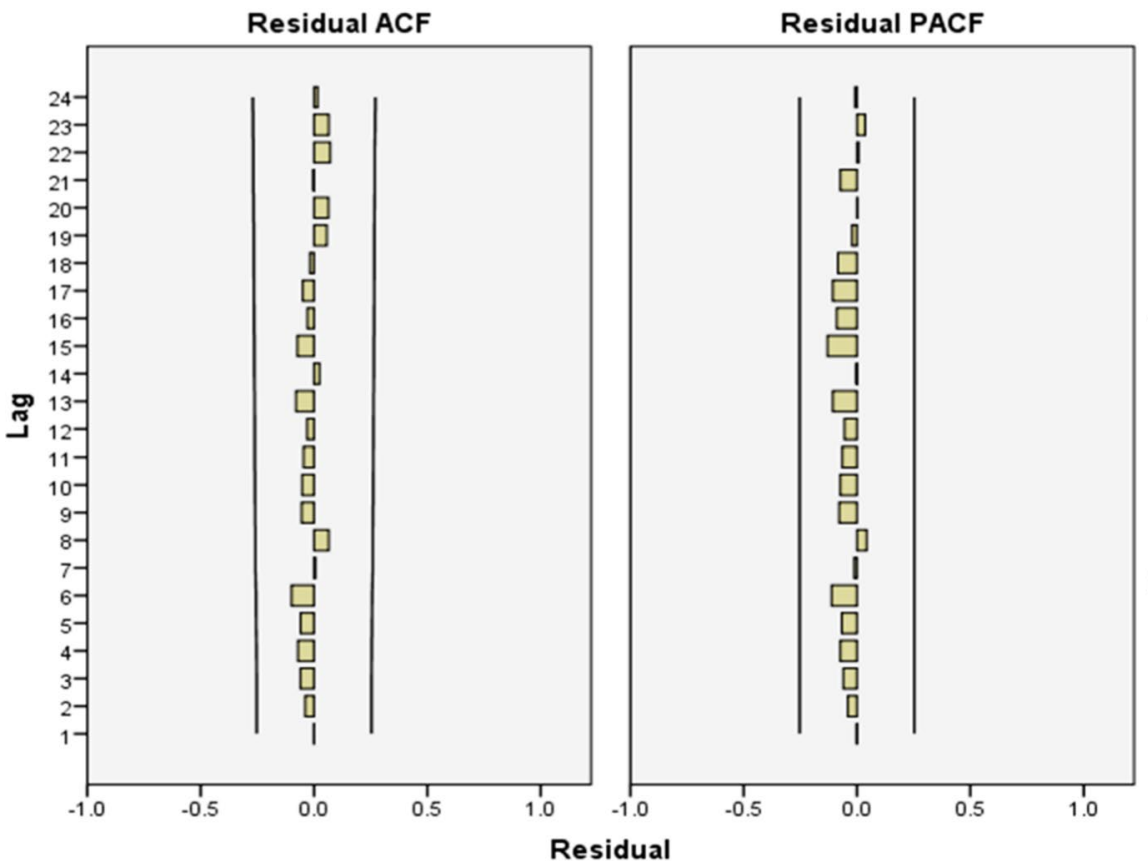

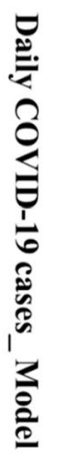

\begin{tabular}{llllllllll}
\hline Parameters & & DHK & CTG & RAJ & SYL & MYM & RAN & BAR & KHU \\
\hline Rainfall (mm) & Maximum & 5.1 & 3.3 & 29.8 & 16.7 & 9.8 & 18.1 & 3.7 & 7.0 \\
& Minimum & 0.0 & 0.0 & 0.0 & 0.0 & 0.0 & 0.0 & 0.0 & 0.0 \\
& Mean & 0.9 & 0.5 & 1.1 & 2.1 & 1.0 & 1.4 & 0.3 & 0.7 \\
& SD & 1.4 & 0.8 & 3.9 & 3.5 & 1.7 & 3.2 & 0.6 & 1.3 \\
& CV (\%) & 1.7 & 1.8 & 3.5 & 1.6 & 1.8 & 2.2 & 2.3 & 2.0 \\
Relative humidity (\%) & Maximum & 75.5 & 85.5 & 89.5 & 88.5 & 87.3 & 94.0 & 75.3 & 76.3 \\
& Minimum & 27.8 & 60.3 & 12.0 & 23.5 & 22.3 & 13.8 & 39.5 & 14.3 \\
& Mean & 56.8 & 76.1 & 48.7 & 65.5 & 58.0 & 52.5 & 66.6 & 64.6 \\
Temperature $\left({ }^{\circ} \mathrm{C}\right)$ & SD & 9.1 & 4.9 & 16.9 & 15.1 & 14.5 & 20.2 & 6.5 & 9.0 \\
& CV (\%) & 0.2 & 0.1 & 0.3 & 0.2 & 0.3 & 0.4 & 0.1 & 0.1 \\
& Maximum & 34.5 & 30.8 & 36.0 & 32.3 & 33.8 & 33.3 & 34.3 & 34.0 \\
& Minimum & 27.0 & 26.5 & 25.0 & 24.5 & 26.0 & 22.8 & 26.0 & 26.5 \\
& Mean & 31.5 & 28.1 & 31.8 & 28.8 & 29.8 & 29.3 & 30.2 & 30.5 \\
Wind speed $\left(\mathrm{km} \mathrm{h}^{-1}\right.$ ) & SD & 1.9 & 1.0 & 2.6 & 1.8 & 1.8 & 2.2 & 1.7 & 1.6 \\
& CV (\%) & 0.1 & 0.0 & 0.1 & 0.1 & 0.1 & 0.1 & 0.1 & 0.1 \\
& Maximum & 37.3 & 37.3 & 37.3 & 15.0 & 29.5 & 46.8 & 30.0 & 31.8 \\
& Minimum & 4.8 & 9.5 & 6.5 & 3.3 & 5.3 & 5.0 & 6.0 & 6.0 \\
& Mean & 14.0 & 15.8 & 12.9 & 6.9 & 11.0 & 12.7 & 14.0 & 14.1 \\
& SD & 6.4 & 5.4 & 5.6 & 2.5 & 4.3 & 6.4 & 5.7 & 5.7 \\
& CV (\%) & 0.5 & 0.3 & 0.4 & 0.4 & 0.4 & 0.5 & 0.4 & 0.4 \\
& M1 April-31 & 4690 & 1590 & 294 & 307 & 210 & 239 & 66 & 94 \\
& May 2020 & & & & & & & & \\
\hline
\end{tabular}

or no rain causes sweating and thus enhances COVID-19 transfer and number of COVID-19 cases may be through sweating droplets from person to person in densely populated cities Dhaka and Chittagong, or infected person's clothes or other surfaces. Similar reasons are reported earlier as well (e.g. Ahmadi et al. 2020; Menebo 2020; Tosepu et al. 2020; Pani et al. 2020). Although the number of positive cases is different in different places, but in general follow temperature and relative humidity trends (see Figs. S1 and S2). Furthermore, (Figs. S1 and S2), it 
has been seen that the COVID-19 cases were substantially low until 18 April 2020 since the first three positive cases registered on 8 March in Dhaka, while in contrast, the dramatic increased rates were found thereafter, following the pattern of increased temperature and relative humidity across the cities in Bangladesh. Among the cities, Dhaka and Chittagong accounted the greater numbers than others (Fig. S2) primarily due to relatively high temperature and humidity with little rainfall, unplanned urban settings with number of informal settlements with a dense population in comparison to other cities.

It is noted that in March, with the inception of COVID-19 cases in Dhaka, the typical weather pattern was seen just like post winter with temperature around $25^{\circ} \mathrm{C}$, relatively low humidity, wind speed and no precipitation. The complete shutdown declared to avoid spreading of COVID-19 transmission from 16 March to 16 April 2020 further controlled the COVID-19 cases. However, resuming business, offices and other activities since 16 April 2020, increased numbers of COVID-19 positive cases in Dhaka and Chittagong, as these two cities are business hub in Bangladesh. The failure to implement controlled lockdown measures in many cities and increased pressures of resumptions of business ultimately saw incremental rate of COVID-19 transmission with lack of health regulations, as reported by similar studies elsewhere (Ahmadi et al. 2020; Menebo 2020; Pani et al. 2020; Tosepu et al. 2020). A very similar happening was observed in Bangladesh after 16 April 2020 along with incremental increase of temperature, relative humidity, which further confirms the observations in aforesaid studies done in other parts of the world.

\section{Correlation in between COVID-19 cases and climatic parameters}

The result of Spearman's rank correlation analysis between climatic parameters and the COVID-19 positive cases have been tabulated in Table 2. A couple of considerations have been taken before correlating the climatic parameters with COVID-19 pandemic. Firstly, the tests were conducted instantly without requirement of any symptoms of COVID19 or a public mass testing campaigns, and for which, the results were given instantly; hence, affected date and climatic information on the same day are valid. Secondly, the tests were done based on symptoms followed by incubation periods as suggested by IEDCR. For example, testing has been conducted for the people having COVID-19 symptoms (e.g., coughing, fever or respiratory difficulties) and keeping one or more symptoms in consideration, the climatic parameters are evaluated for three timeframes, namely, 3 days, 7 days, 14 days before being reported COVID-19 positive. In this line, due to limited kits and testing laboratories in Bangladesh, the test results were delayed in some cases even couple of weeks or so, and hence, it is well understood that the patients got infected earlier than reported date. Therefore, climatic information of 3 days, 7 days or 14 days before declared positive for COVID-19 were considered for the correlation analysis.

Table 2 The correlation coefficients between climatic parameters and COVID-19 positive cases

\begin{tabular}{|c|c|c|c|c|c|c|c|c|}
\hline Variables & DHK & CTG & RAJ & SYL & MYM & RAN & BAR & KHU \\
\hline R (Rain on day) & $0.406^{* *}$ & $0.360 * *$ & $0.252 *$ & $0.283^{*}$ & $0.271^{*}$ & $0.279 *$ & -0.107 & 0.121 \\
\hline R3 (Rain 3 days lag) & $0.279 *$ & $0.431 * *$ & $0.386^{* *}$ & $0.497 * *$ & $0.316^{*}$ & $0.321 * *$ & 0.028 & $0.283^{*}$ \\
\hline R7 (Rain 7 days lag) & $0.241^{*}$ & $0.364 * *$ & 0.050 & $0.341 * *$ & $0.299 *$ & 0.145 & -0.094 & 0.131 \\
\hline R14 (14 days lag) & 0.214 & $0.338 * *$ & 0.128 & 0.131 & 0.123 & $0.245^{*}$ & -0.167 & 0.117 \\
\hline RH (Humidity on day) & $0.581 * *$ & 0.145 & $0.400 * *$ & $0.311 *$ & $0.390 * *$ & $0.411 * *$ & $0.265^{*}$ & $0.295^{*}$ \\
\hline H3 (Humidity 3 days lag) & $0.525 * *$ & 0.056 & $0.568 * *$ & $0.492 * *$ & $0.303 *$ & $0.443 * *$ & 0.176 & $0.357 * *$ \\
\hline H7 (Humidity 7 days lag) & $0.404 * *$ & 0.015 & $0.402 * *$ & $0.502 * *$ & $0.275^{*}$ & $0.390 * *$ & $0.231^{*}$ & 0.209 \\
\hline H14 (Humidity 14 days lag) & $0.432 * *$ & -0.01 & $0.241^{*}$ & $0.242 *$ & $0.337 * *$ & $0.422 * *$ & 0.078 & $0.248^{*}$ \\
\hline T (Temperature on day) & -0.187 & $0.609 * *$ & -0.087 & -0.214 & $-0.272 *$ & 0.067 & -0.045 & -0.063 \\
\hline T3 (Temperature 3 days lag) & -0.124 & $0.721 * *$ & $-0.233^{*}$ & $-0.357 * *$ & -0.086 & -0.058 & -0.058 & -0.018 \\
\hline T7 (Temperature 3 days lag) & -0.13 & $0.676^{* *}$ & -0.051 & $-0.229 *$ & -0.137 & -0.032 & 0.024 & 0.153 \\
\hline T14 (Temperature 14 days lag) & -0.119 & $0.674 * *$ & -0.068 & 0.031 & -0.193 & -0.089 & 0.161 & 0.034 \\
\hline W (Wind speed on day) & 0.082 & 0.081 & 0.067 & -0.048 & $0.279 *$ & 0.234 & -0.076 & 0.027 \\
\hline W3 (Wind speed 3 days lag) & 0.065 & 0.191 & 0.132 & -0.049 & -0.082 & 0.033 & -0.099 & 0.098 \\
\hline W7 (Wind speed 7 days lag) & 0.090 & 0.141 & $0.246^{*}$ & 0.140 & 0.017 & 0.076 & $0.317 * *$ & $0.241^{*}$ \\
\hline W14 (wind speed 14 days lag) & 0.156 & 0.117 & $0.293 *$ & 0.132 & 0.151 & $0.253^{*}$ & $0.369 * *$ & $0.255^{*}$ \\
\hline
\end{tabular}

**Correlation is significant at the 0.01 level

*Correlation is significant at the 0.05 level 
As can be observed from the data in Table 2, the correlation coefficients are found to be varied among the cities in Bangladesh. The association of climatic parameters with COVID-19 cases exhibit both positive and negative relationship with their magnitudes vary between poor to strong. Similar findings of positive and negative correlation coefficients are also reported in previous studies from different cities (Ahmadi et al. 2020; Menebo 2020; Pani et al. 2020; Tosepu et al. 2020) as presented in Table 3. For example, Ahmadi et al. (2020) has investigated on the effects of climatology parameters on COVID-19 outbreak in Iran and found that temperature and rainfall have positive relationship and humidity, wind speed and solar radiation have negative effects on COVID-19 outbreak in terms of infected cases. Another study by Biktasheva (2020) found that local air humidity has negative correlation with COVID-19 mortality in German federal states. In this line, positive correlation for diurnal temperature $(r=0.44)$ but negative for relative humidity $(\mathrm{r}=-0.32)$ with COVID-19 daily mortality counts in Wuhan, China were reported by Ma et al. (2020). This study also revealed that absolute humidity has a positive correlation with the death counts. In contrast, Qi et al. (2020) reported both average temperature and average humidity are negatively correlated with COVID-19 transmission in Mainland China and very similar findings with climatic variables have been reported by Şahin (2020) for 9 major cities in Turkey. Furthermore, Menebo (2020) noted the maximum, minimum, normal and average temperatures, alongwith wind speed have positive association with daily new cases, while precipitation exhibits negative association in Oslo, Norway. Another study on similar criteria by Tosepu et al. (2020) reported that the temperature, humidity and rainfall have positive association with the COVID-19 cases in Jakarta, Indonesia.

Moreover, in general, temperature (except in Chittagong city), showed negative association with positive cases although the number of statistically significant correlations are few (Table 2). In contrast, strong positives and greater number of associations with all four times frame in Chittagong city put the opposite impression in comparison to other cities. The relatively strong easterly wind may carry the contaminated air droplets in addition to temperature and relative humidity might explain the significant positive correlations with the temperature and COVID-19 positive cases in Chittagong in comparison to other cities. Considering relative humidity, the greater number of significant positive correlations with a magnitude range $0.231-0.581$ were seen across the cities. In general, 3 and 7 days earlier relative humidity data has shown a greater number of relatively strong correlations with the positive cases than on date and 14 days earlier data. The result indicates that higher humidity favors the transmission of COVID-19. Similar findings were also reported by Pani et al. (2020) in their study in Singapore. Temperature and humidity both are well documented with both positive and negative associations, portraying different forms of thoughts and influences on transmission of

Table 3 Association of climatic parameters with COVID-19 cases reported in different studies

\begin{tabular}{|c|c|c|c|c|c|c|c|}
\hline Study area & $\begin{array}{l}\text { Rainfall in } \mathrm{mm} \\
\text { (Coef.) }\end{array}$ & $\begin{array}{l}\text { Temp in }{ }^{\circ} \mathrm{C} \\
\text { (Coef.) }\end{array}$ & $\begin{array}{l}\text { Relative humid- } \\
\text { ity in } \% \\
\text { (Coef.) }\end{array}$ & $\begin{array}{l}\text { Wind speed in } \\
\mathrm{km} \mathrm{h}^{-1} \\
\text { (Coef.) }\end{array}$ & $\begin{array}{l}\text { COVID-19 } \\
\text { cases }\end{array}$ & Time period & References \\
\hline $\begin{array}{l}\text { Cities in Bang- } \\
\text { ladesh }\end{array}$ & $\begin{array}{l}3.3-29.8 \\
(0.241-0.497\end{array}$ & $\begin{array}{l}22.8-34.5 \\
(-0.229 \text { to } \\
\quad+0.721)\end{array}$ & $\begin{array}{l}12-94 \\
(0.241-0.581)\end{array}$ & $\begin{array}{l}3.3-46.8 \\
(0.241-0.369)\end{array}$ & 7490 (Total) & $\begin{array}{l}8 \text { Mar-31 May } \\
2020\end{array}$ & This Study \\
\hline Cities in Iran & $\begin{array}{l}20.03 \pm 8.37 \\
(0.029)\end{array}$ & $\begin{array}{l}8.32 \pm 4.55 \\
(0.028)\end{array}$ & - & $\begin{array}{l}12.73 \pm 2.30 \\
(-0.358)\end{array}$ & $660 \pm 906$ & $\begin{array}{l}19 \text { Feb-22 Mar } \\
2020\end{array}$ & $\begin{array}{l}\text { Ahmadi et al. } \\
\text { (2020) }\end{array}$ \\
\hline Wuhan, China & $\mathrm{n} / \mathrm{a}$ & $\begin{array}{l}7.44 \pm 3.96 \\
(0.30)\end{array}$ & $\begin{array}{l}82.24 \pm 8.51 \\
(-0.32)\end{array}$ & $\mathrm{n} / \mathrm{a}$ & $\mathrm{n} / \mathrm{a}$ & $\begin{array}{l}20 \mathrm{Jan}-29 \mathrm{Feb} \\
2020\end{array}$ & Ma et al. (2020) \\
\hline Oslo, Norway & $\begin{array}{l}1.19 \\
(-0.285)\end{array}$ & $\begin{array}{l}4.76 \\
(0.224)\end{array}$ & $\mathrm{n} / \mathrm{a}$ & $\begin{array}{l}11.95 \\
(0.174)\end{array}$ & 37 & $\begin{array}{l}27 \text { Feb-2May } \\
2020\end{array}$ & Menebo (2020) \\
\hline Mainland China & $\mathrm{n} / \mathrm{a}$ & $\begin{array}{l}-16.9 \text { to } 19.3 \\
\text { (n/a) }\end{array}$ & $\begin{array}{l}17.93-86.20 \\
(\mathrm{n} / \mathrm{a})\end{array}$ & $\mathrm{n} / \mathrm{a}$ & $3125(\max )$ & $\begin{array}{l}20 \mathrm{Jan}-11 \mathrm{Feb} \\
2020\end{array}$ & Qi et al. (2020) \\
\hline Cities in Turkey & $\mathrm{n} / \mathrm{a}$ & $\begin{array}{l}11.8-17.7 \\
(-0.483)\end{array}$ & $\begin{array}{l}93.6(\max ) \\
(-0.317)\end{array}$ & $\begin{array}{l}49.41(\max ) \\
(-0.217)\end{array}$ & 16,787 (Total) & $\begin{array}{l}21 \mathrm{Mar}-03 \mathrm{Apr} \\
2020\end{array}$ & Şahin (2020) \\
\hline $\begin{array}{l}\text { Jakarta, Indo- } \\
\text { nesia }\end{array}$ & $\begin{array}{l}1.1-88 \\
(0.139)\end{array}$ & $\begin{array}{l}26.1-28.6 \\
(0.392)\end{array}$ & $\begin{array}{l}75-93 \\
(0.002)\end{array}$ & - & 61 & $\begin{array}{l}1 \text { Jan-29 Mar } \\
2020\end{array}$ & $\begin{array}{l}\text { Tosepu et al. } \\
\text { (2020) }\end{array}$ \\
\hline Spain & - & $\begin{array}{l}15.44 \pm 2.63 \\
(0.234)\end{array}$ & - & - & $618.4 \pm 648.04$ & April 2020 & $\begin{array}{l}\text { Shahzad et al. } \\
(2020)\end{array}$ \\
\hline India & $\begin{array}{l}1445 \pm 855 \\
(-0.285)\end{array}$ & $\begin{array}{l}22.30 \pm 7.33 \\
(0.269)\end{array}$ & - & $\begin{array}{l}5.97 \pm 1.764 \\
(0.178)\end{array}$ & $949 \pm 1728$ & April 2020 & $\begin{array}{l}\text { Gupta et al. } \\
(2020)\end{array}$ \\
\hline
\end{tabular}

Correlation coefficients are kept within bracket 
COVID-19 cases. While, Pani et al. (2020), Tosepu et al. (2020), Xie and Zhu (2020) reported positive linear relationship between temperature and the number of positive cases from China, Indonesia and Singapore respectively, the inverse relationship was noted by Holtmann et al. (2020), Liu et al. (2020), Méndez-arriaga (2020) from their studies in China, Mexico, Spain and Germany, respectively. On the contrary, Yao et al. (2020) reported no such significant correlation between temperature and COVID-19 transmission. This study revealed that both high temperature and humidity can explain better positive association in case of COVID-19 transmission in warmer regions. Unlike other studies, this study also investigated the influence of precipitation on COVID-19 transmission, as in Bangladesh June, July and August belong to monsoon period receiving significant amount of precipitation. As seen in Table 2, precipitation in general, showed positive although poor to fair associations ( $\mathrm{r}=0.241-0.341)$ with COVID-19 cases for 3 and 7 days earlier than reported positive cases. This illustrates that precipitation may further increase the transmission if social distancing and health regulations are not maintained in flood shelters. Similar positive correlation with precipitation was reported by Ahmadi et al. (2020) from Iran. In the case of wind speed, positive correlations $(r=0.241-0.369)$ were found with the COVID-19 confirmed cases for 7 and 14 days earlier than reported cases. Similar to this study, Menebo (2020) in Oslo, Norway, Bashir et al. (2020) in New York, USA and Şahin (2020) in Turkey reported positive correlation with wind speed and COVID-19 cases. However, negative correlation with wind speed of 14 days before the reported positive cases was also noted by Menebo (2020) and on day wind speed by Pani et al. (2020).

Table 3 presents summary of few studies highlighting effects of climatic parameters on COVID-19 transmission. The results indicate that an increase in unit of any parameters that are positively correlated with the COVID-19 cases may pose relatively greater risk of transmission. As seen in
Table 3, the correlation coefficients associated with the different climatic variables for the present study are better in magnitude than other studies elsewhere. The differences are due to the number of records, heterogenity of the climatic parameters, lockdown periods, urban landscape, population density etc., as reported by studies tabulated here. In relation to Bangladesh climate, this is a warning for warmer weather and for other regions of the world with similar weather patterns elswhere. Bangladesh may face severity of COVID19 transmission at community scale unless necessary health regulations and control measures are taken. Furthermore, in Bangladesh, the effectiveness of lockdown, people's perception to COVID-19, willingness to follow the health regulations were hardly seen to work so far and hence, increased rate of positive cases are found with the increasing temperature and humidity. The harsh reality of COVID-19 thurst is yet to be seen if it continues as usual.

\section{COVID-19 pandemic: future trends for Bangladesh}

This study investigates the COVID-19 pandemic trends in relation to climate, and to forsee the transmission simulating present trends assuming that the lifestyle may continue as usual in Bangladesh. This investigation may not only assist health care policymakers but also local council/upazilla administration in order to prepare tasks ahead with necessary measures to avoid loss of lives and widespread COVID19 cases. For forecasting and prediction of COVID-19 cases, ARIMA model has been established with a data of 60 days starting from 1st April 2020, and is shown in Fig. 4.

The model shows daily mean values along with upper and lower bound confidences while estimating the number of COVID-19 positive cases ahead. As seen in Fig. 4, the forecasting of COVID-19 spans for 190 days from April 1, 2020 to September 10, 2020. The highest positive cases are predicted by the model on day 91, i.e., 31 July 2020 with a magnitude close to 4000 . This daily rate is seen to
Fig. 4 Future trends of COVID19 cases predicted for Bangladesh

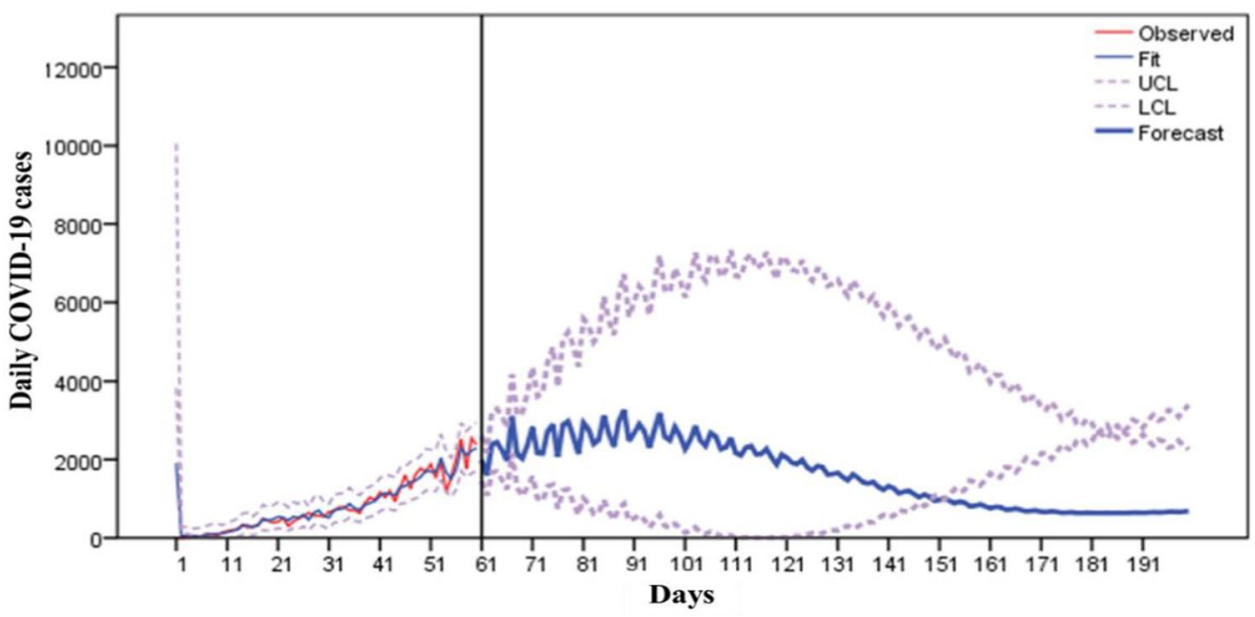


last for another 10 days to 10 August 2020, and thereafter is seen falling gradually to the 171th day, that is $1 \mathrm{st}$ September 2020. The model predicted the value of daily cases in the month of June 2020 with a deviation of $+10 \%$ with respect to mean in few cases, and hence were found in good agreement with the climatic variables and daily reported COVID-19 positive cases. This study, therefore, presents a new insight, providing an estimated COVID19 cases in addition to the influences of meteorological parameters on COVID-19 transmission. It is anticipated that the study will assist policymakers and people in Bangladesh to declare warning systems and adoption of best management practices for vulnerable groups, while in case of failure to do so the rate may follow the upper confidence level, where it is seen almost doubled than mean daily rate and the country may see the worst situation ever for COVID-19 cases. However, this study also acknowledges the limitations, such as genome structure and variations of SARS-Cov-2 virus and its adaptability to various climatic patterns of different regions, consideration of gender speciation of the data alongwith different age groups, population density, economic variables, willingness to follow health guidelines declared time to time by WHO and local health care departments, which can be investigated in relation to COVID-19 pandemic. Nevertheless, the study may help to forecast the ongoing COVID-19 pandemic for Bangladesh and also for regions with similar weather patterns in South East Asian belt.

\section{Conclusion}

This study explored the effects of daily temperature, rainfall, wind speed and relative humidity on COVID-19 cases in Bangladesh with four different time frames, and investigated their association with the registered cases. Moreover, this study demonstrates a model for prediction of COVID-19 cases in relation to climatic parameters. The findings suggest greater number of relatively strong positive associations between the relative humidity and positive cases than are with rainfall and wind speed, while temperature showed both positive and negative associations. In context of predictive trend of COVID-19 cases, ARIMA model potrays a total span of almost 7 months from its inception on 8 March 2020 in Bangladesh. The peak of positive cases are in the end of July associated with rainfall, humidity and temperature. It is therefore reasonable to take appropriate health regulations based on climate to contain COVID-19 cases and death toll in Bangladesh.

Supplementary Information The online version contains supplementary material available at https://doi.org/10.1007/s42398-021-00195-5.
Author contributions SKP (Professor): Conceptualization, Methodology, Writing — review \& editing, Visualization, Project administration, supervision. MdMHM (PG Student): Conceptualization, Methodology, Investigation, Formal analysis, Writing - original draft.

Funding No funding has been received for this research.

Data availability The data and materials will be made available upon request.

\section{Declarations}

Conflict of interest The authors declare that they have no known competing financial interests or personal relationships that could have appeared to influence the work reported in this paper.

\section{References}

Ahmadi M, Shari A, Dorosti S, Jafarzadeh S, Ghanbari N (2020) Investigation of effective climatology parameters on COVID-19 outbreak in Iran. Sci Total Environ 729:138705. https://doi.org/10. 1016/j.scitotenv.2020.138705

Bashir MF, Ma B, Bilal KB, Bashir MA (2020) Correlation between climate indicators and COVID-19 pandemic in New York. Sci Total Environ 728:138835. https://doi.org/10.1016/j.scitotenv. 2020.138835

Biktasheva IV (2020) Role of a habitat's air humidity in Covid-19 mortality. Sci Total Environ 736:138763. https://doi.org/10.1016/j. scitotenv.2020.138763

BMD (2020) Bangladesh Meteorological Department. http://www. bmd.gov.bd/. Accessed 15 July 2020

DGHS (2020) Directorate General of Health Services. https://dghs.gov. bd/index.php/en/home. Accessed 24 July 2020

Gupta A, Banerjee S, Das S (2020) Significance of geographical factors to the COVID-19 outbreak in India. Model Earth Syst Environ. https://doi.org/10.1007/s40808-020-00838-2

Haque M, Ahamad R (2020) Over 500 RMG units reopen in Bangladesh amid coronavirus risks. NEWAGE. https://www.newagebd. net/

Holtmann M, Jones M, Shah A, Holtmann G (2020) Low ambient temperatures are associated with more rapid spread of COVID-19 in the early phase of the endemic. Environ Res 186(April):109625. https://doi.org/10.1016/j.envres.2020.109625

IEDCR (2020) Distribution of Confirmed cases in Bangladesh. Institute of Epidemiology, Disease Control and Research (IEDCR). https:// iedcr.gov.bd/

Kerimray A, Baimatova N, Ibragimova OP, Bukenov B, Kenessov B, Plotitsyn P, Karaca F (2020) Assessing air quality changes in large cities during COVID-19 lockdowns: the impacts of trafficfree urban conditions in Almaty, Kazakhstan. Sci Total Environ 730:139179. https://doi.org/10.1016/j.scitotenv.2020.139179

Liu J, Zhou J, Yao J, Zhang X, Li L, Xu X, He X, Wang B (2020) Impact of meteorological factors on the COVID-19 transmission: a multi-city study in China. Sci Total Environ 726:138513. https:// doi.org/10.1016/j.scitotenv.2020.138513

Ma Y, Zhao Y, Liu J, He X, Wang B, Fu S, Yan J, Niu J, Zhou J, Luo B (2020) Effects of temperature variation and humidity on the death of COVID-19 in Wuhan, China. Sci Total Environ 724:138226. https://doi.org/10.1016/j.scitotenv.2020.138226

Masum MH, Pal SK (2021) Statistical evaluation of selected air quality parameters influenced by COVID-19 lockdown. Glob J Environ 
Sci Manag 6(SI):85-94. https://doi.org/10.22034/GJESM.2019. 06.SI.08

Méndez-arriaga F (2020) The temperature and regional climate effects on communitarian COVID-19 contagion in Mexico throughout phase 1. Sci Total Environ 735(139560):1-23. https://doi.org/10. 1016/j.scitotenv.2020.139560

Menebo MM (2020) Temperature and precipitation associate with Covid-19 new daily cases: a correlation study between weather and Covid-19 pandemic in Oslo, Norway. Sci Total Environ 737:139659. https://doi.org/10.1016/j.scitotenv.2020.139659

Pani SK, Lin N, Ravindrababu S (2020) Association of COVID-19 pandemic with meteorological parameters over Singapore. Sci Total Environ 740(January):140112. https://doi.org/10.1016/j. scitotenv.2020.140112

Qi H, Xiao S, Shi R, Ward MP, Chen Y, Tu W, Su Q, Wang W, Wang $X$, Zhang Z (2020) COVID-19 transmission in Mainland China is associated with temperature and humidity: a time-series analysis. Sci Total Environ 728:138778. https://doi.org/10.1016/j.scitotenv. 2020.138778

Şahin M (2020) Impact of weather on COVID-19 pandemic in Turkey. Sci Total Environ 728:138810. https://doi.org/10.1016/j.scitotenv. 2020.138810

Shahzad K, Shahzad U, Iqbal N, Shahzad F, Fareed Z (2020) Effects of climatological parameters on the outbreak spread of COVID19 in highly affected regions of Spain. Res Sq. https://doi.org/10. 21203/rs.3.rs-30377/v1

Shawon AA (2020) Coronavirus: Bangladesh declares public holiday from March 26 to April 4. Dhaka Tribune. https://www.dhaka tribune.com/
Spearman C (2008) Spearman rank correlation coefficient. In: The concise encyclopedia of statistics. Springer New York, pp 502-505. https://doi.org/10.1007/978-0-387-32833-1_379

Tobías A, Carnerero C, Reche C, Massagué J, Via M, Minguillón MC, Alastuey A, Querol X (2020) Changes in air quality during the lockdown in Barcelona (Spain) one month into the SARS-CoV-2 epidemic. Sci Total Environ 726:138540. https://doi.org/10. 1016/j.scitotenv.2020.138540

Tosepu R, Gunawan J, Savitri D, Ode L, Imran A, Lestari H, Bahar H, As $\mathrm{P}$ (2020) Correlation between weather and Covid-19 pandemic in Jakarta, Indonesia. Sci Total Environ 725:138436. https://doi. org/10.1016/j.scitotenv.2020.138436

Xie J, Zhu Y (2020) Association between ambient temperature and COVID-19 infection in 122 cities from China. Sci Total Environ 724:138201. https://doi.org/10.1016/j.scitotenv.2020.138201

Yao Y, Pan J, Liu Z, Meng X, Wang W, Kan H, Wang W (2020) No association of COVID-19 transmission with temperature or UV radiation in Chinese cities. Eur Respir J 55(2000517):1-5. https:// doi.org/10.1183/13993003.00517-2020

Publisher's Note Springer Nature remains neutral with regard to jurisdictional claims in published maps and institutional affiliations. 